Page-5, Figure -4 , Table -2

Supporting information for:

\title{
pH dependence of phosphorus speciation and transport in flow- electrode capacitive deionization
}

Yanhong Bian, Xi Chen, Zhiyong Jason Ren ${ }^{*}$

Department of Civil and Environmental Engineering and the Andlinger Center for Energy and the Environment, Princeton University, Princeton, NJ 08544, USA

*Corresponding author address: Department of Civil and Environmental Engineering, Princeton University, Princeton, NJ 08544, USA; Tel:+1 (609) 258-7580;E-mail: zjren@princeton.edu 

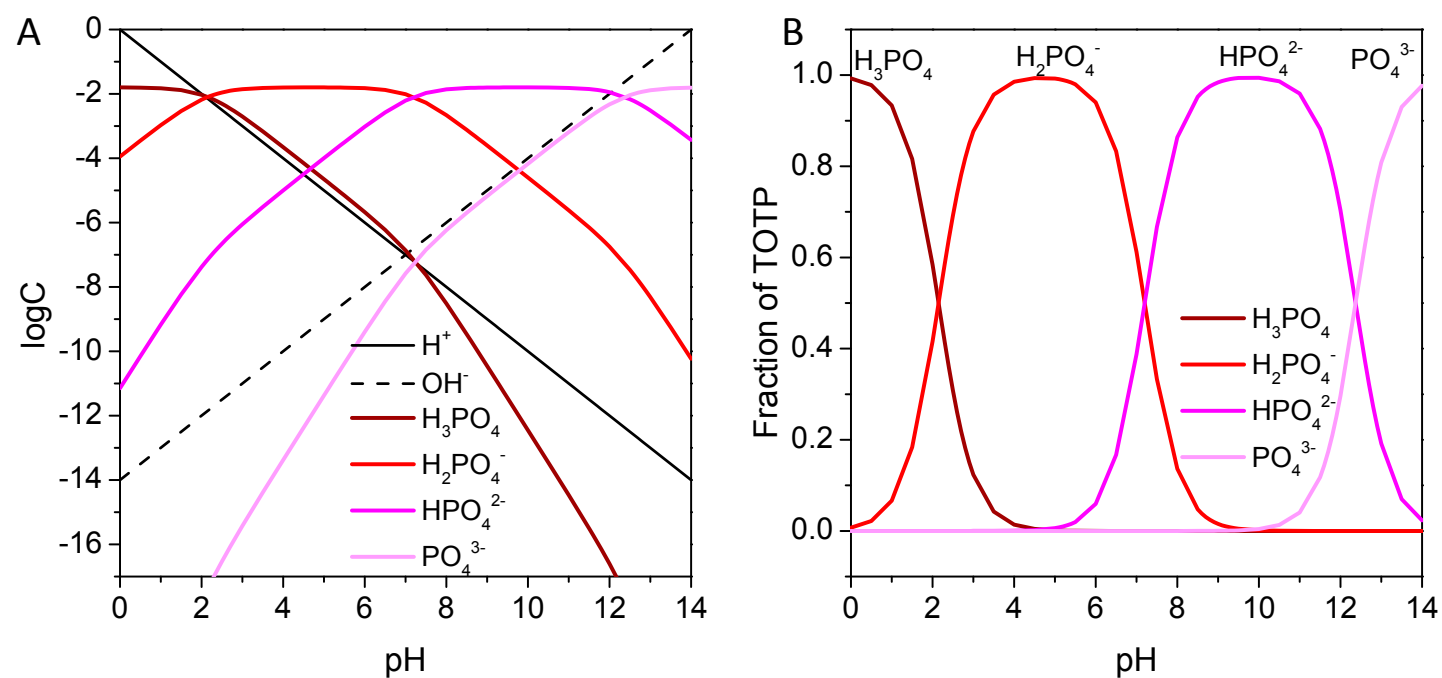

Fig. S1 Speciation diagram of $\mathrm{P}$ species from $\mathrm{pH} 0$ to $\mathrm{pH} 14$ (initial TOTP=16 mmol). (A) $\log$ C-pH diagram (B) Fraction of $\mathrm{P}$ species.

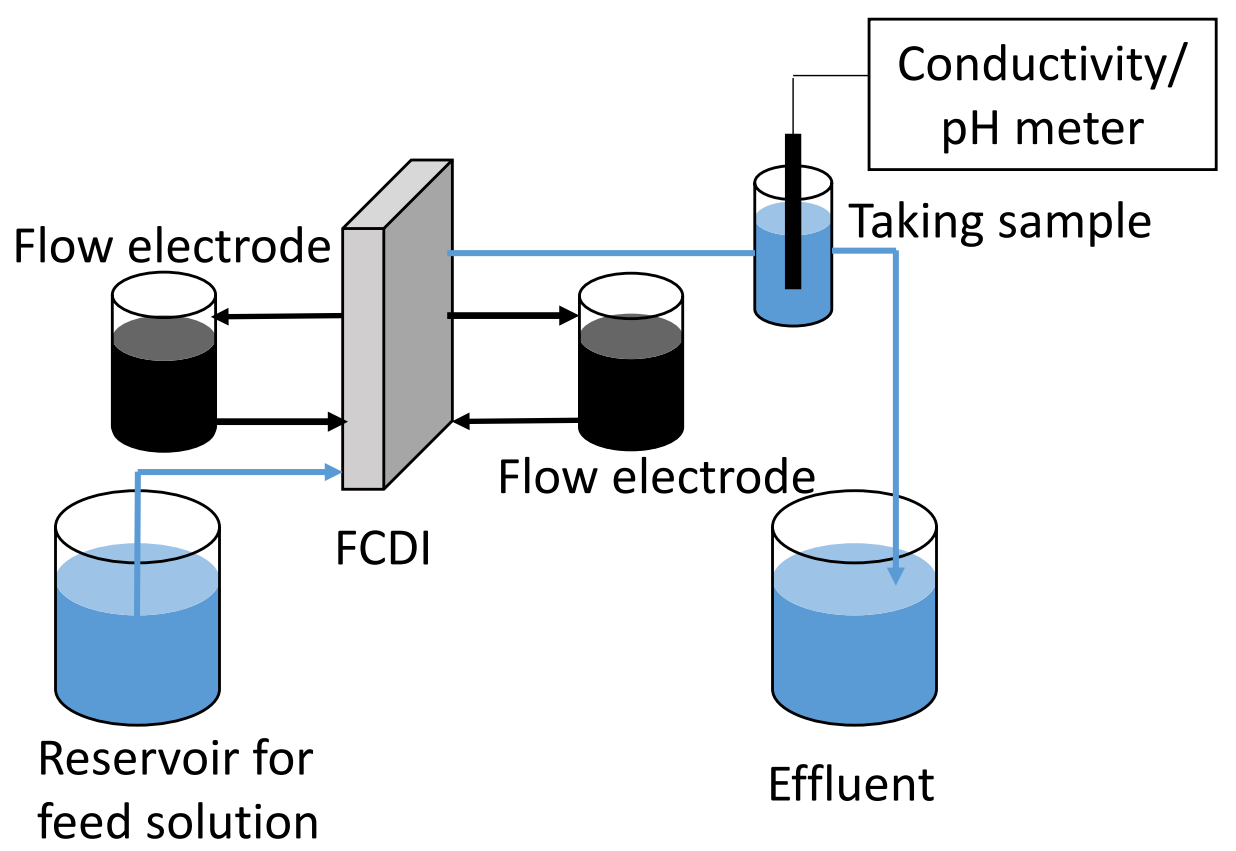

Fig. S2 Schematic diagram of the single-pass FCDI 


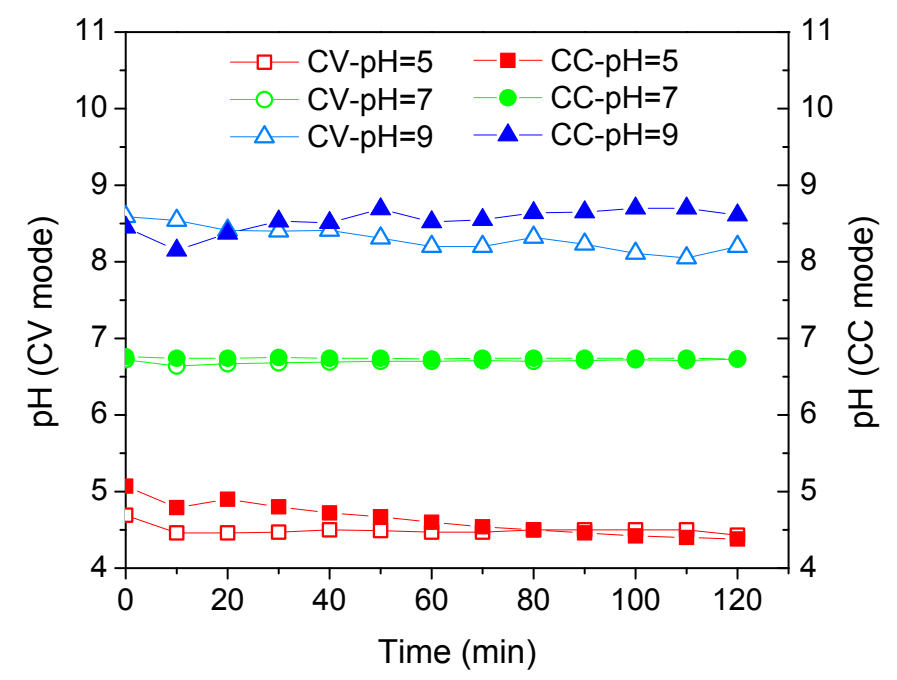

Fig.S3 Variation of effluent $\mathrm{pH}$ under different initial feed solution $\mathrm{pH}$ values from 5 to 9. The open symbol refers to the $\mathrm{pH}$ under $\mathrm{CV}$ charging mode and solid symbol refers to the $\mathrm{pH}$ under $\mathrm{CC}$ charging mode. The flow-electrodes used in these tests were 10 $\mathrm{wt} \%$ of activated carbon in DI water with an initial $\mathrm{pH}$ around 6.5 .

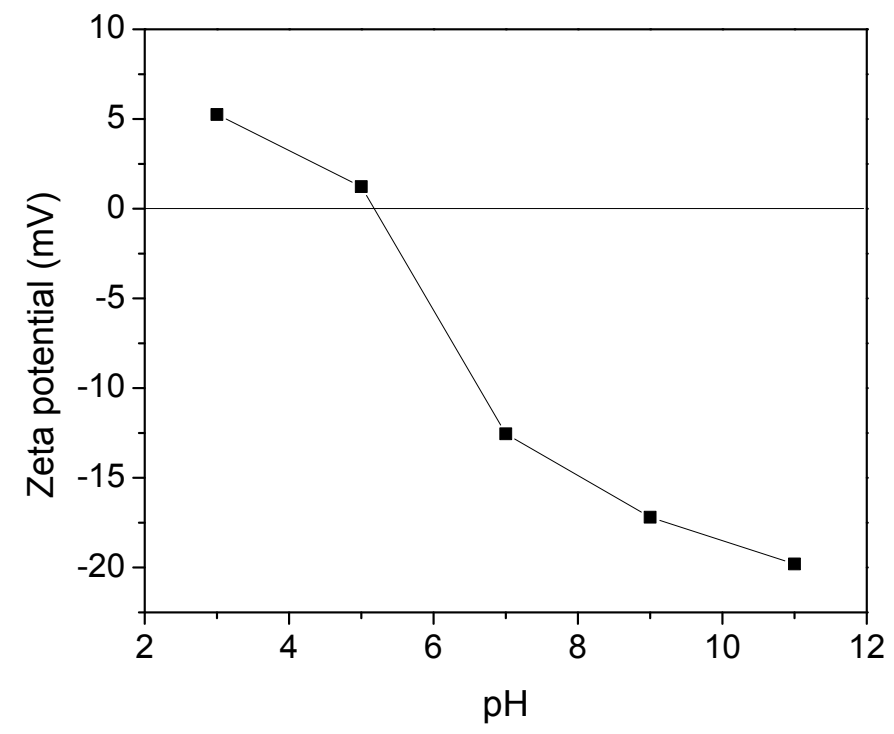

Fig.S4 Zeta potential of activated carbon at different $\mathrm{pHs}$

Table S1 Current efficiency of P removal with different feed solution $\mathrm{pHs}$ in different charging modes

\begin{tabular}{cccc}
\hline Charging mode & \multicolumn{3}{c}{ Current efficiency (\%) } \\
\cline { 2 - 4 } & $\mathrm{pH}=5$ & $\mathrm{pH}=7$ & $\mathrm{pH}=9$ \\
\hline CV mode & $\sim 74 \pm 2.4$ & $\sim 77 \pm 2.2$ & $\sim 71 \pm 1.8$ \\
\hline CC mode & $\sim 75 \pm 4.5$ & $\sim 72 \pm 5.8$ & $\sim 67 \pm 4.7$ \\
\hline
\end{tabular}


Table S2 Energy consumption of $\mathrm{P}$ removal with different electrolyte $\mathrm{pH}$ during charging stage (feed solution $\mathrm{pH}=7$ )

\begin{tabular}{ccccc}
\hline \multicolumn{5}{c}{ Energy consumption $(\mathrm{kWh} / \mathrm{kg} \mathrm{P})$} \\
\hline $\mathrm{pH}=3$ & $\mathrm{pH}=5$ & $\mathrm{pH}=7$ & $\mathrm{pH}=9$ & $\mathrm{pH}=11$ \\
\hline$\sim 0.92 \pm 0.018$ & $\sim 0.97 \pm 0.031$ & $\sim 0.96 \pm 0.043$ & $\sim 0.91 \pm 0.028$ & $\sim 0.89 \pm 0.015$ \\
\hline
\end{tabular}

\section{Current efficiency calculation}

The current efficiency of $\mathrm{P}$ removal (\%) was determined by using equation $\mathrm{S} 1$ :

Current efficiency $=\frac{\sum \int_{0}^{t} n_{x} F Q\left(C_{0, x}-C_{t, x}\right) d t}{M \int_{0}^{t} I d t}$

where $\mathrm{C}_{0, x}$ and $\mathrm{C}_{\mathrm{t}, \mathrm{x}}$ were phosphate ions $\left(\mathrm{H}_{2} \mathrm{PO}_{4}^{-}, \mathrm{HPO}_{4}{ }^{2-}, \mathrm{PO}_{4}{ }^{3-}\right)$ in initial and effluent solutions (mg P/L), respectively; $n_{x}$ was the ion charge ( 1 for $\mathrm{H}_{2} \mathrm{PO}_{4}^{-}, 2$ for $\mathrm{HPO}_{4}{ }^{2-}$ and 3 for $\left.\mathrm{PO}_{4}{ }^{3-}\right) ; \mathrm{F}$ was the Faraday constant $(96485 \mathrm{C} / \mathrm{mol}) ; \mathrm{M}$ was the molar mass of phosphorus $(\mathrm{g} / \mathrm{mol}) ; \mathrm{Q}$ was the flow rate $(\mathrm{L} / \mathrm{s})$; $\mathrm{t}$ was the charging time (s); and I was applied current (A).

The concentrations of different phosphate species (either $\mathrm{C}_{0, x}$ or $\mathrm{C}_{t, \mathrm{x}}$ ) can be expressed as a function of $\mathrm{pH}$ and total phosphorus concentration based on mass balance and equilibrium reactions. In detail, the phosphate ions concentration can be determined by equations (S2-S4):

$$
\begin{aligned}
& C_{\mathrm{H}_{2} \mathrm{PO}_{4}^{-}}=\frac{C_{T P}}{\frac{\left\{\mathrm{H}^{+}\right\}}{K_{a 1}}+1+\frac{K_{a 2}}{\left\{\mathrm{H}^{+}\right\}}+\frac{K_{a 2} K_{a 3}}{\left\{\mathrm{H}^{+}\right\}^{2}}} \\
& C_{\mathrm{HPO}_{4}{ }^{2-}}=\frac{C_{T P}}{\frac{\left\{\mathrm{H}^{+}\right\}^{2}}{K_{a 1} K_{a 2}}+\frac{\left\{\mathrm{H}^{+}\right\}}{K_{a 2}}+1+\frac{K_{a 3}}{\left\{\mathrm{H}^{+}\right\}}}
\end{aligned}
$$




$$
C_{P O_{4}^{3-}}=\frac{C_{T P}}{\frac{\left\{\mathrm{H}^{+}\right\}^{3}}{K_{a 1} K_{a 2} K_{a 3}}+\frac{\left\{\mathrm{H}^{+}\right\}^{2}}{K_{a 2} K_{a 3}}+\frac{\left\{\mathrm{H}^{+}\right\}}{K_{a 3}}+1}
$$

Where $\mathrm{C}_{\mathrm{TP}}$ was the total phosphorus concentration (mg P/L); $\left\{\mathrm{H}^{+}\right\}$was the proton activity and was determined by the solution $\mathrm{pH}\left(\left\{\mathrm{H}^{+}\right\}=10^{-\mathrm{pH}}\right) ; \mathrm{K}_{\mathrm{a} 1}, \mathrm{~K}_{\mathrm{a} 2}$ and $\mathrm{K}_{\mathrm{a} 3}$ were equilibrium constants and their negative log values were $\mathrm{pK}_{\mathrm{a} 1}$ $=2.148, \mathrm{pK}_{\mathrm{a} 2}=7.198$ and $\mathrm{pK}_{\mathrm{a} 3}=12.375$, respectively. 